American Journal of Biotechnology and Biochemistry 3 (1): 10-15, 2007

ISSN 1553-3468

(C) 2007 Science Publications

\title{
The Crude Aqueous Extract of Piper betle L. and its Antibacterial Effect Towards Streptococcus mutans
}

\author{
T. Nalina and Z.H.A. Rahim \\ Department of Oral Biology, Faculty of Dentistry, University of Malaya, 50603 Kuala Lumpur, Malaysia
}

\begin{abstract}
In this study, the antimicrobial influence of crude aqueous extract of Piper betle L. on Streptococcus mutans (S. mutans) was investigated. The focus of the antimicrobial effects includes the ultrastructure and acid producing properties of $S$. mutans. Transmission electron microscopy (TEM) was used to determine the effect of the extract on the ultrastructure of $S$. mutans. Analysis of the effect on the acid producing properties was analyzed by $\mathrm{pH}$ drop assay. The investigation was further carried out to determine the possible chemical components of the extract using thin layer chromatography (TLC), bioautography and gas chromatography mass spectrometry (GCMS). From the micrographs of the transmission electron, it was found that the crude extract of Piper betle L. leaves causes plasma cell membrane damage and coagulation of the nucleoid. The extract was found to significantly reduce acid producing properties of the bacteria. Chemical analysis of the extract showed that hydroxychavicol, fatty acids (stearic and palmitic) and hydroxy fatty acid esters (stearic, palmitic and myristic) as the main components. It was suggested from the results obtained that the crude extract of Piper betle $\mathrm{L}$. leaves may exert anticariogenic activities that are related to decrease in acid production and changes to the ultrastructure of $S$. mutans. Further study will be carried out to determine if the effect observed is attributed to the presence of hydroxychavicol, fatty acids and hydroxy fatty acid esters in the extract.
\end{abstract}

Key words: S. mutans, Piper betle L., antimicrobial, bioautography, acid production

\section{INTRODUCTION}

In the South East Asia region, Piper betle L. (sireh) are among the plants that have been associated with the control of caries and periodontal diseases ${ }^{[1]}$ and to the control of bad breath ${ }^{[2]}$. Fathilah et al. ${ }^{[3]}$ have reported that the crude aqueous extract of Piper betle L. leaves exhibits antibacterial activity towards Streptococcus mitis, Streptococcus sanguis and Actinomyces viscosus, some of the early colonizers of dental plaque.

The microbial etiology of caries involves oral pathogens and ecological shifts in dental plaque in response to increased sugar challenge or decreased salivary flow in the oral cavity ${ }^{[4]}$. The bacteria that are most closely associated with caries development are the mutans streptococci, which are known to possess high acidogenic and aciduric properties, together with their ability to synthesize extracellular glucans from sucrose catalysed by GTFs. Their virulence is related directly to their capacity to adhere and produce acids from glycolysis in dental plaque at $\mathrm{pH}$ values of 4.0 or even lower ${ }^{[5]}$. There are many ways of chemotherapeutic avenues other than eliminating $S$. mutans selectively; this includes reduction of glucan formation by GTFs and reduction in the ability of the organism to produce acids.

Most of the studies on plant extracts ${ }^{[6-9]}$ have demonstrated their antibacterial activities towards $S$. mutans. The antibacterial activities may be attributed to reduced growth, reduced adhering ability and reduced glucosyl transferase activity. The adherence of the early colonizers prepares the environment conducive for the colonization of the secondary colonizers like Strep. mutans $^{[4]}$. Razak and Rahim ${ }^{[10]}$ have reported that the aqueous extract of Piper betle L. inhibits adherence of early plaque settlers, which include Streptococcus mitis, Streptococcus sanguinis and Actinomyces sp. to salivacoated glass surfaces. In this way, extract of Piper betle L. leaves indirectly inhibits the adherence of $S$. mutans by making the environment not conducive for $S$. mutans to adhere. The extract also exhibited potent inhibitory properties against the growth of $S$. mutans and activity of glucosyltransferase $(\mathrm{GTF})^{[11]}$. The inhibition of glucosyl transferase will affect the formation of glucan which subsequently will make the environment less conducive for the growth of $S$. mutans.

Thus, it has been shown that the crude extract of Piper betle L. leaves exhibits antibacterial activity 
towards $S$. mutans by affecting the adhering property, growth and formation of glucan ${ }^{[11]}$. In this study, the objective was to investigate the effect of the extract on ultrastructure and acid production of $S$. mutans. In addition, the chemical components of the extract were also determined.

\section{MATERIALS AND METHODS}

Plant material: Piper betle L. leaves were obtained from one source in Mentakab, Pahang.

Preparation of bacterial suspension: The $S$. mutans ATCC 25175 was obtained commercially from the American Type Culture Collection, USA. The stock of these bacteria was kept in glycerol at $-70{ }^{\circ} \mathrm{C}$ for further use. The bacterial suspension was prepared according to the method previously described by Nalina and Rahim $^{[11]}$.

Preparation of crude aqueous extract of Piper betle L. by decoction: The crude aqueous extract was prepared according to the procedure that have been reported $^{[11]}$.

Analysis of acid production: Sterile crude aqueous Piper betle L. extract (final concentration of 1, 2, 5, 10 $\mathrm{mg} \mathrm{mL} \mathrm{m}^{-1}$ ) was added to $13 \times 150 \mathrm{~mm}$ tubes containing $20 \mathrm{ml}$ of BHI broth and $1 \%$ glucose. $100 \mu$ l of the seed culture of mutans streptococci was then inoculated into the broth medium. During the incubation at $37^{\circ} \mathrm{C}, 1 \mathrm{~mL}$ of the culture was periodically scooped up and its $\mathrm{pH}$ was measured with a pH meter (Model pH 213, Hanna Instruments) according to the method described by Ooshima et al. ${ }^{[12]}$.

Cell ultrastructure study: Prior to the transmission electron microscopy (TEM) study, the bacteria culture was prepared according to the procedure described below.

Bacterial cultures and growth: Streptococcus mutans ATCC 25175 primary cultures were grown in brain heart infusion broth to the late log phase of growth (optical density of 1.20 at $550 \mathrm{~nm}$ ). Cell pellets were washed three times in ice-cold distilled water and suspended in broth to an optical density of 0.144 at 550 $\mathrm{nm}$ immediately before assays were performed.

Treatment of the bacteria with the plant extract: Cell suspension $(10 \mathrm{~mL})$ was preincubated at $37^{\circ} \mathrm{C}$ for $1 \mathrm{~h}$ and then treated with the respective $1 \mathrm{mg} \mathrm{mL}^{-1}$ and 2 $\mathrm{mg} \mathrm{mL} \mathrm{m}^{-1}$ of crude $P$. betle L. leaves extract. The mixture (final volume; $100 \mathrm{~mL}$ ) was left to incubate for $2 \mathrm{hrs}$. Mouthrinse containing chlorhexidine $(0.12 \%)$ and sterile deionised water was used as positive and negative control, respectively. After the $2 \mathrm{hrs}$ incubation, the treated bacterial cells were precipitated by centrifugation and processed for electron microscopy.

Transmission electron microscopy (TEM) study: The control and the $P$. betle L. leaves extract treated cells were fixed in $4 \%$ glutaraldehyde and later postfixed in $1 \%$ osmium tetraoxide $(0.1 \mathrm{M}$ cacodylate buffer, $\mathrm{pH}$ 7.4) at room temperature. After eliminating the remaining osmium tetraoxide, the samples were dehydrated in a graduated cold ethanol series (35 to $100 \%$ ). Each step was performed for about 10 to 15 mins at room temperature. The fixed cells were embedded with Epon and the small blocks of bacteria were cut with an ultramicrotome (Ultracut, Reichert). The ultra thin sections were then analyzed using TEM (Libra 120, Leo).

Analysis of the chemical components of the extract: The crude aqueous extract of Piper betle L (10mg) was analyzed by TLC on Silica Gel G plates $(20 \times 10 \mathrm{~cm})$ (Macherey-Nagel) using solvent system chloroform (Mallinckrodt) - methanol (Fisher Scientific) (90:10). Three sets of TLC plates (A, B, C) were prepared. Plate $\mathrm{A}$, the reference chromatogram was used to determine the spots as visualized by UV irradiation (254 and $366 \mathrm{~nm}$ ), plate B was used for bioautography and plate $\mathrm{C}$ was used to identify spots with phenolic compound. 25\% Folin Ciocalteu phenol reagent (Sigma Chemical Co.) was used to identify spots with phenolic compound. To plate $\mathrm{C}$, tannic acid (Sigma Chemical Co.) was added and used as reference for phenolic compound. $R_{f}$ values of the spots separated on the TLC plates were determined. The $R_{f}$ value for a substance is the ratio of the distance that the substance travels to the distance that the solvent travels up the plate.

Bioautography: Chromatogram developed as described above was placed in a sterile bioassay petri dish (NUNC) and an inoculum of Strep. mutans containing $10^{6} \mathrm{CFU} \mathrm{mL} \mathrm{m}^{-1}$ in molten BHI agar (OXOID) was distributed over the plates. After solidification of the medium, the sterile bioassay petri dish with the TLC plate was incubated at $37{ }^{\circ} \mathrm{C}$ for $24 \mathrm{hrs}$. The $\mathrm{R}_{\mathrm{f}}$ of the inhibition zones on plate $B$ was compared with the $R_{f}$ of reference chromatogram (plate A). The corresponding spots that showed antibacterial activity were scraped and collected and used in the gas chromatography-mass spectrometry study. 
Analysis of the chemical components of the extract by Gas chromatography-mass spectrometry (GCMS): The scrapings of spots with the antibacterial activity were then dissolved in ethanol and centrifuged to remove silica. The supernatant collected were then filtered with a $0.45 \mu \mathrm{m}$ filter and evaporated to dryness. The trimethysilyl (TMS) derivatives of the extract were prepared using $N, O$-bis (trimethylsilyl) trifluoroacetamide (BSTFA, Aldrich, St Louis, MO). About $3 \mathrm{mg}$ of the extract was derivatized in $300 \mu \mathrm{L}$ of BSTFA by heating for $60 \mathrm{~min}$ at $60^{\circ} \mathrm{C}$ and analyzed using GCMS. The analyses were obtained in gas chromatography (Agilent GC 5973N) equipment with mass selective detector (Agilent G2589A) in the electron impact ionization mode, capillary column SGE BPX5 $(30 \mathrm{~m} \times 0.25 \mathrm{~mm} \times 0.25 \mu \mathrm{m})$. The instrumentation procedure was according to the method described by Uzel et al. ${ }^{[13]}$.

The percentage of each compound was calculated as the ratio of the peak area to the total chromatographic area. The GCMS peaks were identified by comparison with several data reported by other researchers ${ }^{[14-16]}$ and the profiles from the Wiley $7 \mathrm{n}$ and Nist 98 libraries.

Statistical analysis: Each experiment was carried out in triplicates and repeated three times. Thus the data in this study was computed and expressed as mean \pm standard deviation from nine determinations. Inter group difference was estimated by statistical analysis of variance (ANOVA) for factorial model.

\section{RESULTS AND DISCUSSION}

Figure 1 shows the profile of the effect of crude aqueous extract of Piper betle L. towards S. mutans. $1 \mathrm{mg} \mathrm{mL}^{-1}$ of the extract reduced the rate of acid production to $93.53 \%$. Increasing the concentration further to 2, 5 and $10 \mathrm{mg} \mathrm{mL}^{-1}$ reduced the rate of acid production to $88.20,40.51$ and $23.56 \%$ respectively.

Figures $2 \mathrm{~A}$ to $2 \mathrm{~F}$ are the electron micrographs showing cytological effects of the Piper betle L. leaves extract towards $S$. mutans. Figure $2 \mathrm{~A}$ is the electron micrograph of the blank control and it was observed that the cells have well-defined outer cell and dense

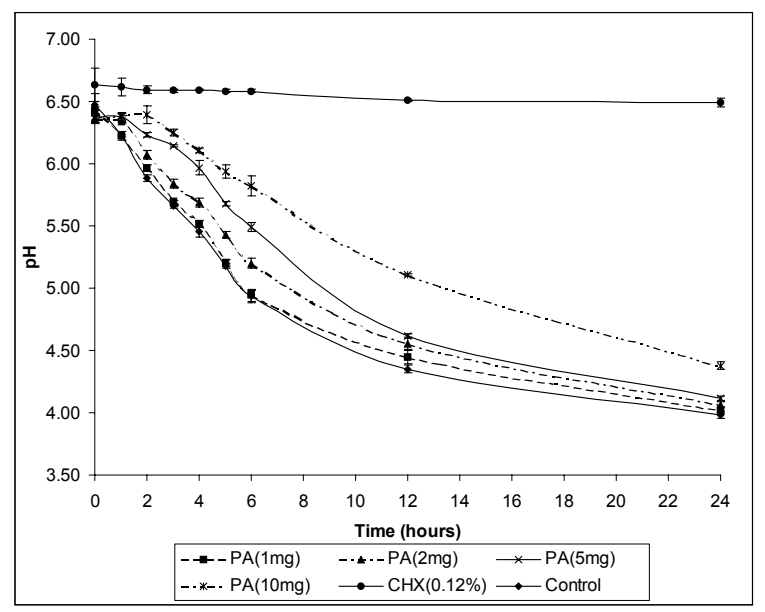

Fig. 1: Effect of different concentrations of crude aqueous extract Piper betle L. leaves on the acid production of S. mutans. PA(1mg) - Crude aqueous Piper betle L. extract $1 \mathrm{mg} \mathrm{mL}^{-1}$, PA(2mg) - Crude aqueous Piper betle L. extract $2 \mathrm{mg} \mathrm{mL}^{-1}$, PA(5mg) - Crude aqueous Piper betle L. leaves extract $5 \mathrm{mg}$ $\mathrm{mL}^{-1}$, PA(10mg) - Crude aqueous Piper betle L. leaves extract $10 \mathrm{mg} \mathrm{mL}^{-1}$, Control - Sterile deionised water indicated by the lowest graph; CHX - Chlorhexidine $0.12 \%$ $(\mathrm{v} / \mathrm{v})$ indicated by the top most graph, $(\mathrm{p}<0.01$ except at 0 hour; Intergroup differences were estimated by ANOVA). The $\mathrm{pH}$ values are expressed as the mean \pm standard deviation from nine determinations.

inner cell walls and intact plasma cell membranes. Figure 2B shows the electron micrograph of $S$. mutans treated with mouth-rinse containing chlorhexidine $(0.12 \%)$. This serves as a positive control. It was observed that the nucleoid and plasma cell membrane disintegrate and the cytoplasm leaches out from the cells while the cell remains intact. This indicates that lysis is occurring at an early stage.

It was observed that upon exposure to the crude extract of the Piper betle L. leaves, the ultrastructure of $S$. mutans was affected (Figures. 2C-2F). The effect of the treatment with $1 \mathrm{mg} \mathrm{mL}^{-1}$ of the extract is shown in Figures $2 \mathrm{C}$ and $2 \mathrm{D}$ and that of $2 \mathrm{mg} \mathrm{mL}^{-1}$ is shown in Figures $2 \mathrm{E}$ and $\mathrm{F}$. All of the micrographs showed cells with nucleoid material coagulated into thick electrondense filaments and destruction of the plasma cell membrane and inner cell wall. The effect is more significant with the higher concentration of the extract.

Figure 3 shows the chemical components of the crude extract of Piper betle L. leaves as separated using TLC. Plate A is the chromatogram showing separation of the components on TLC. The components of the extract separated into one big spot and two or more smaller spots. Plate B is the chromatogram treated with bacterial inoculum to determine the spots with antibacterial zone. Of the number of spots observed, the bigger spot exhibited the antibacterial activity with 


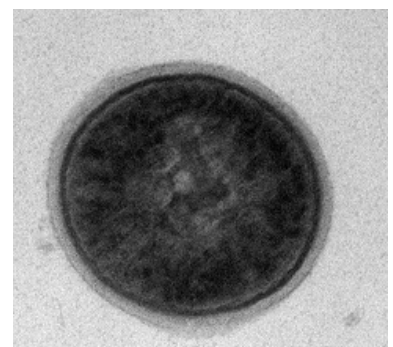

A (magnification: $31500 x)$

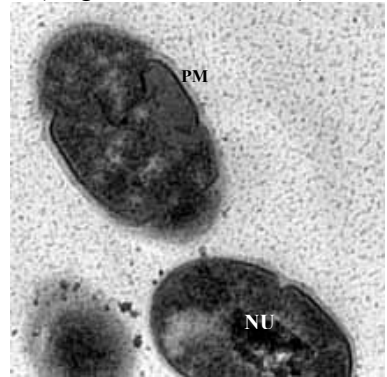

C (magnification: 12500x)

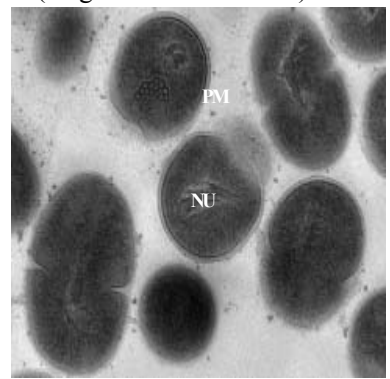

E (magnification: 10000x)

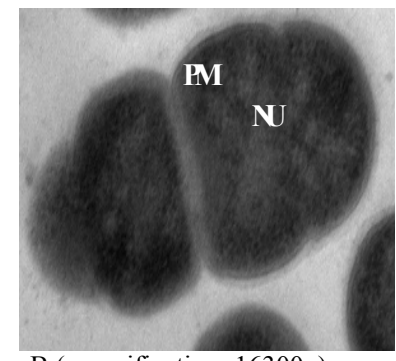

B (magnification: 16300x)

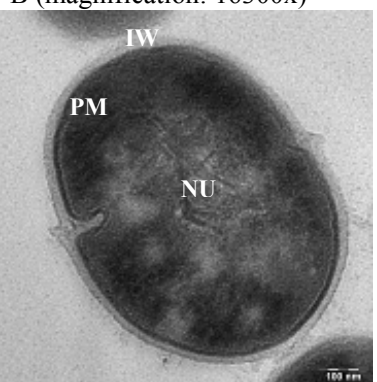

D (magnification: 25000x)

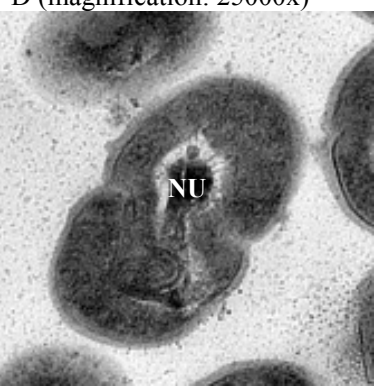

F (magnification: 16300x)

Fig. 2: Cytological effects of Piper betle L. leaves extract on $S$. mutans. A shows control (treated with sterile deionised water) and $\mathrm{B}$ is cells treated with mouthrinse containing chlorhexidine $(0.12 \%)$. C and D shows electron micrograph of S.mutans treated with crude $P$. betle L. leaves extract $(1 \mathrm{mg}$ $\mathrm{mL}^{-1}$ ) and $\mathrm{E}$ and $\mathrm{F}$ shows S.mutans treated with crude $P$. betle L. leaves extract $\left(2 \mathrm{mg} \mathrm{mL}^{-1}\right)$. NU - nucleoid, PMplasma cell membrane, IW - inner cell wall, OW - outer cell wall

diameter of the inhibition zone measuring $30 \pm 0.86$ $\mathrm{mm}$ (mean \pm Standard deviation from nine determinations). Plate $\mathrm{C}$ is the chromatogram sprayed with $25 \%$ Folin-Ciocalteu phenol reagent to locate the spots with phenolic compound. All of the spots stained positive for phenolic component. The bigger spot which has an $R_{f}$ values between 0.82 to 0.91 corresponds to the inhibition zone on the plate B. No inhibition zone was observed corresponding to the spots with the $R_{f}$ values below 0.82 .

The chromatogram of GCMS of the Piper betle L. leaves extract is shown in Fig. 4 and the relative percentage of the identified compounds is summarized in Table 1. It was found that the main constituents of

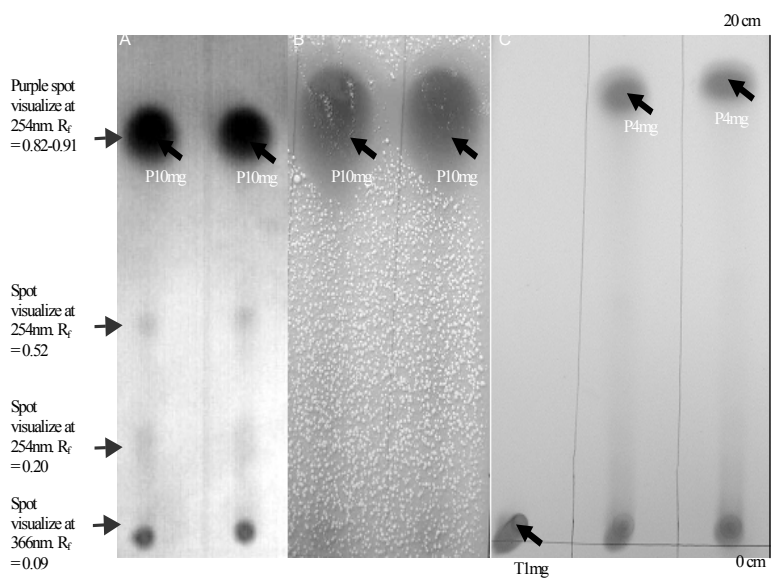

Fig. 3: Thin layer chromatography plates were run in triplicates and one set was visualized as above (plate A), the other set was used for bioautography with Streptococcus mutans (plate B) as described in the methodology and the third set (plate C) was sprayed with $25 \%$ Folin Ciocalteu phenol reagent to identify spots with phenolic compound. Arrow indicates antibacterial activity at $R_{f}$ values between 0.82 to 0.91 . Spots were visualized by UV irradiation (254 and $366 \mathrm{~nm})$. T1 Tannic acid $(1 \mathrm{mg} / \mathrm{ml})$ as control for phenolic content, P4mg Crude aqueous Piper betle L. leaves extract $4 \mathrm{mg} \mathrm{mL}^{-1}$, P10mg - Crude aqueous Piper betle L. extract $10 \mathrm{mg} \mathrm{mL}^{-1}$

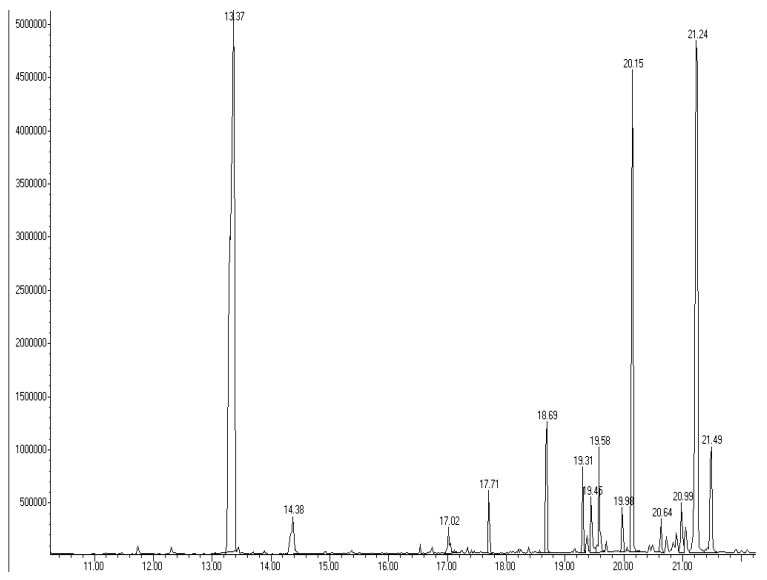

Fig. 4: $\quad$ Chromatogram of Piper betle L. leaves extract

the extract correspond to hydroxychavicol (39.31\%), fatty acids [stearic (3.77\%) and palmitic (1.60\%)], hydroxybenzeneacetic acid (3.96\%) and hydroxy esters of fatty acids [stearic $(24.49 \%)$, palmitic $(14.71 \%)$ and myristic $(1.58 \%)]$.

Natural products are in great demand due to its extensive biological properties and providing source for the discovery of many types of effective bioactive compounds. Piper betle L. has been recognized for their many pharmacological activities such as its antioxidant ${ }^{[17,18]}$ and antibacterial properties ${ }^{[3,6-9,11,15,]}$. 
Am. J. Biochem. \& Biotech., 3 (1): 10-15, 2007

\begin{tabular}{|c|c|c|c|c|c|}
\hline No. & Compounds & $\begin{array}{l}\text { TMS } \\
\text { groups }\end{array}$ & Ions selected $(\mathrm{m} / \mathrm{z})$ & $\begin{array}{l}\text { Retention time } \\
\text { (min) }\end{array}$ & Area $(\%)$ \\
\hline 1 & Hydroxychavicol* & 2 & $294\left(\mathrm{M}^{+}\right), 205,73$ & 13.37 & 39.31 \\
\hline 2 & $\begin{array}{l}\text { Benzeneacetic acid, alpha- } \\
\text { hydroxyphenyl }\end{array}$ & 2 & $284(\mathrm{M}+), 269,240,73$ & 17.02 & 0.95 \\
\hline 3 & Hexadecanoic acid & 1 & $328(\mathrm{M}+), 313,145,117,73$ & 17.71 & 1.60 \\
\hline 4 & Octadecanoic acid & 1 & $356(\mathrm{M}+), 341,201,145,117,73$ & 18.69 & 3.77 \\
\hline 5 & $\begin{array}{l}\text { Myristic acid,2,3-bis(hydroxy)propyl } \\
\text { ester }\end{array}$ & 2 & $\begin{array}{l}446(\mathrm{M}+), 431, \quad 343,211, \quad 147, \\
103,73\end{array}$ & 19.31 & 1.58 \\
\hline 6 & Hexadecanamide & 0 & $255(\mathrm{M}+), 86,59$ & 19.46 & 1.46 \\
\hline 7 & n.d. & & & 19.98 & 1.06 \\
\hline 8 & $\begin{array}{l}\text { Hexadecanoic acid,2,3- } \\
\text { bis(hydroxy)propyl ester }\end{array}$ & 2 & $\begin{array}{l}474(\mathrm{M}+), 459,371,313,239, \\
147,103,73\end{array}$ & 20.15 & 14.71 \\
\hline 9 & n.d. & & & 20.64 & 0.88 \\
\hline 10 & 2-Monopalmitin & 2 & $\begin{array}{l}474(\mathrm{M}+), 313,218,191,129, \\
103,73\end{array}$ & 20.99 & 1.56 \\
\hline 11 & $\begin{array}{l}\text { Octadecanoic acid,2,3- } \\
\text { bis(hydroxy)propyl ester }\end{array}$ & 2 & $\begin{array}{l}502(\mathrm{M}+), 487,399,341,267, \\
205,147,103,73\end{array}$ & 21.24 & 24.49 \\
\hline 12 & Benzeneacetic acid, alpha-hydroxy & 2 & $296(\mathrm{M}+), 281,179,105,73$ & 21.49 & 3.96 \\
\hline
\end{tabular}

Hexadecanoic acid - palmitic acid

Octadecanoic acid - stearic acid

Hexadecanoic acid,2,3-bis(hydroxy)propyl ester - palmitic acid,2,3-bis(hydroxy)propyl ester

Octadecanoic acid,2,3-bis(hydroxy)propyl ester - stearic acid acid,2,3-bis(hydroxy)propyl ester

* values obtained by calculation of mass.

n.d. - not determined

It was found that the extract of Piper betle L. leaves contains fatty acids (stearic acid and palmitic acid) and hydroxy fatty acid esters (hydroxy esters of stearic, palmitic and myristic acids) and hydroxychavicol, with the latter as main component. This is in accordance with what have been reported ${ }^{[14-}$ 16]. The hydroxychavicol is said to exhibit antibacterial activity ${ }^{[19]}$. Fatty acids can act as anionic surfactants and have antibacterial and antifungal properties at low $\mathrm{pH}^{[20]}$, in addition to being selective against Grampositive organisms ${ }^{[21]}$ by targeting the structure and function of bacterial cell walls and membranes. These components may be the contributing factors to the effect demonstrated by the crude extract of Piper betle L., reducing the acid producing activity and affecting the ultrastructure of $S$. mutans.

The inhibition of acid production is related to the energy producing process or glycolysis. It was found that the reducing effect on acid production is comparable to the reduction in its growth rate, in the presence of the extract at similar concentrations ${ }^{[11]}$. The fatty acids present in the extract could act at the glycolytic enzymes which may be one of the attributing factors to its antibacterial activity as have been reported $^{[22-25]}$.

The effect of the crude extract on the ultrastructure of $S$. mutans observed in this study could be due to the fatty acids and hydroxy fatty acid ester components present. The hydrophobic parts of the compound may enable them to partition the lipids of the bacterial cell membrane, thereby disturbing the structures and rendering them more permeable. When the membrane is more permeable, other components present in the extract could make its way into the bacterium and coagulate the nucleoid while maintaining the cell intact. However, further studies need to be carried out to ascertain the mechanism involved in the biological activities of these compounds.

\section{ACKNOWLEDGEMENTS}

This study was supported financially through Vote $\mathrm{F}$ (University of Malaya, Kuala Lumpur) and an IRPA Grant (Ministry of Science and Technology, Malaysia).

\section{REFERENCES}

1. Ponglux, D., Wong, S., Phadungcharoen, T., Ruangrungsri, N. and Likhitwitaya, K., 1987. Medicinal Plants, Victory Power Point Corp, Bangkok, pp: 194-209.

2. Ong, H.C. and Nordiana, M., 1999. Malay ethnomedico botany in Machang, Kelantan, Malaysia. Fitoterapia, 70: 502-513.

3. Fathilah, A.R., Bakri M.M. and Rahim, Z.H.A., 2000. Pascasidang Simposium Sains Kesihatan Kebangsaan ke-3. Fakulti Sains Kesihatan Bersekutu, UKM: 216-219. 
4. Marsh, P.D., 2003. Are dental diseases examples of ecological catastrophes? Microbiology, 149: 279294.

5. Sturr, M.G. and Marquis, R.E., 1992. Comparative acid tolerances and inhibitor sensitivities of isolated F-ATPases of oral lactic acid bacteria. Appl. Environ. Microbiol., 58: 2287-2291.

6. Katsura, H., Tsukiyama, R., Suzuki, A. and Kobayashi, M., 2001. In vitro antimicrobial activities of bakuchiol against oral microorganisms. Antimicrobial Agents and Chemother., 45: 3009-3013.

7. Hwang, J-K, Shim, J-S. and Chung, J-Y., 2004. Anticariogenic activity of some tropical medicinal plants against Streptococcus mutans. Fitoterapia, 75: 596-598.

8. Limsong, J., Benjavongkulchai, E. and Kuvatanasuchati, K., 2004. Inhibitory effect of some herbal extracts on adherence of Streptococcus mutans. J. Ethnopharmacol., 92: 281-289.

9. Bakri, I.M. and Douglas, C.W.I., 2005. Inhibitory effect of garlic extract on oral bacteria. Arch. Oral Biol., 50: 645-651.

10. Razak, F.A. and Rahim, Z.H.A., 2003. The antiadherence effect of Piper betle L. and Psidium guajava extracts on the adhesion of early settlers in dental plaque to saliva-coated glass surfaces. J. Oral Sci., 45: 201-206.

11. Nalina, T. and Rahim, Z.H.A., 2006. Effect of Piper betle L. leaf extract on the virulence activity of Streptococcus mutans-an in vitro study. Pak. J. Biol. Sci., 9: 1470-1475.

12. Ooshima, T., Osaka, Y., Sasaki, H., Osawa, K., Yasuda, H., Matsumura, M., Sobue S. and Matsumoto, M., 2000. Caries inhibitory activity of cacao bean husk extract in in vitro and animal experiments. Arch. Oral Biol., 45: 639-645.

13. Uzel, A., Sorkun, K., Oncag, O., Cogulu, D., Gencay, O. and Salih, B., 2005. Chemical compositions and antimicrobial activities of four different Anatolian propolis samples. Microbiolog. Res., 160: 189-195.

14. Liao, Y.L., Chiang, Y.C., Tsai, T.F., Lee, R.F., Chan, Y.C. and Hsiao, C.H., 1999. Contact leukomelanosis induced by the leaves of Piper betle L. (Piperaceae): A clinical and histopathologic survey. J. Am. Acad. Dermatol., 40: 583-589.
15. Ramji, N., Iyer, R. and Chandrasekharan, S., 2002. Phenolic antibacterials from Piper betle in the prevention of halitosis. J. Ethnopharmacol., 83: 149-152.

16. Bhattacharya, S., Mula, S., Gamre, S., Kamat, J.P., Bandyopadhyay, S.K. and Chattopadhyay, S., 2007. Inhibitory property of Piper betel extract against photosensitization-induced damages to lipids and proteins. Food Chem., 100: 1474-1480.

17. Choudhury, D. and Kale, R.K., 2002. Antioxidant and non-toxic properties of Piper betle leaf extract: In vitro and in vivo studies. Phytother. Res., 16: 461-466.

18. Jeng, J.H., Chen, S.Y., Liao, C.H., Tung, Y.Y., Lin, B.R., Hahn, L.J. and Chang, M.C., 2002. Modulation of platelet aggregation by areca nut and betle leaf ingredients: Roles of reactive oxygen species and cyclogenase. Free Rad. Biol. Med., 32: 860-871.

19. Pauli, A., 2002. Antimicrobial Properties of Catechol Derivatives; 3rd World Congress on Allelopathy, Tsukuba, Japan, Aug. 26-30.

20. Hayes, M.L. and Berkovitz, B.K., 1979. The reduction of fissure caries in Wistar rats by a soluble salt of nonanoinic acid. Arch. Oral Biol., 24: 663-666.

21. Kabara, J.J., Swieczkowski, D.M., Conley, A.J. and Truant, J.P., 1972. Fatty acids and derivatives as antimicrobial agents. Antimicrobial Agents and Chemother., 2: 23-28.

22. Sheu, C.W. and Freese, E., 1972. Effects of fatty acids on growth and envelope proteins of Bacillus subtilis. J. Bacteriol., 111: 516-524.

23. Booth, I.R., 1985. Regulation of cytoplasmic $\mathrm{pH}$ in bacteria. Microbiolog. Rev., 49: 329-378.

24. Iwami, Y., Schachtele C.F. and Yamada, T., 1995. Effect of sucrose monolaurate on acid production, levels of glycolytic intermediates and enzyme activities of Streptococcus mutans NCTC 10449. J. Dental Res., 74: 1613-1617.

25. Marshall, D.L., Cotton, L.N. and Bal'a, F.A., 2000. Acetic Acid. In A. S. Naidu (Ed.), Natural Food Antimicrobial Systems. Boca Raton, FL, USA: CRC Press, pp: 61-688. 